\title{
A relação entre Mito e Ciência: o sentido do conhecimento
}

\section{The relationship between Myth and Science: the meaning of knowledge}

\author{
ANDRÉ LUIZ PICOLLI DA SILVA ${ }^{1}$ / ALESSANDRA DE REZENDE RAMOS²
}

Neste texto será abordado a relação entre o Mito e a Ciência, ou mais especificamente, sobre a relação entre o Mito e o Cientista.

Algumas pessoas pensam que a ciência é uma evolução do pensamento filosófico, que por sua vez é uma evolução do pensamento mítico, e que, após alcançado um alto grau de evolução na ciência, o pensamento mítico pôde ser descartado como algo de um passado rudimentar, primitivo e já superado (Chauí, 2004). Mas isso não é verdade, o Mito está entre nós, nem que seja pelo fato dele ser uma construção humana e, portanto, um objeto de estudo nas Ciências Humanas. Mais do que isso, o Mito ainda está vivo porque ele nunca foi superado pela Filosofia e pela Ciência, pela simples razão de que sua função é diferente da função da Filosofia e da Ciência. Então, alguém poderia perguntar: afinal o que é o Mito? Qual a função do Mito?

Geralmente se diz que o Mito é uma explicação fantasiosa, ilusória, irracional sobre as coisas (Bock, Furtado, Teixeira, 1993). Na academia, fala-se muito isso, numa tentativa de contrapor o Mito à Ciência. O Mito seria um tipo de pensamento que forneceria explicações irracionais enquanto a Ciência forneceria explicações racionais sobre o mundo.

Entretanto, essa definição é no mínimo superficial sobre o que seria o Mito (para não dizer preconceituosa), associando o conceito de Mito a uma forma pouco desenvolvida, ou pouco elaborada de pensamento. Essa explicação é equivocada, porque o Mito não pretende explicar nada, logo, ele não pode ser uma explicação irracional.

Nas palavras Joseph Campbel, um dos maiores mitólogos, o Mito: "É o que dá sentido a experiência de estar vivo" (Campbel, 1990), ou seja, a função do Mito não é explicar, mas sim dar sentido as coisas. Por isso o saber mítico não se opõe ao saber filosófico ou científico, pelo contrário, existe uma complementação de saberes, onde o Mito busca dar sentido àquilo que a Filosofia e a Ciência explicam. Por essa razão, o Mito hoje está tão vivo em nossa existência quanto estava na existência dos nossos antepassados no paleolítico. Eles continuam reverberando dentro de nós, pois como também disse Campbel (1990), "os mitos são narrativas de coisas externas que ressoam no nosso interior de modo que realmente sintamos que fazemos parte de um todo maior que nossa experiência individual".

${ }^{1}$ Universidade Federal do Sul e Sudeste do Pará. E-mail: picolli@unifesspa.edu.br ${ }^{2}$ Universidade Federal do Sul e Sudeste do Pará. E-mail: rezende@unifesspa.edu.br 
Talvez hoje não nos emocionemos ouvindo histórias sobre o conflito entre Pai e Filho nas narrativas das disputas entre Kronos e seu filho Zeus, ou ainda ouvindo histórias sobre o sofrimento de uma mãe ao saber do destino trágico de uma filha, como na história de Deméter e Core, que depois de ser raptada por Hades, Deus do submundo, passou a se chamar Persefone. Contudo, muitos se emocionaram vendo a história do conflito entre Darth Vader e seu filho Lucky Skywalker em Guerra nas Estrelas, ou ainda quando Daenerys Targaryen, a mãe de dragões, teve que prender seus filhos nas masmorras de Meereen, ou quando Cersei teve que enterrar todos os seus filhos em Game of Thrones.

A emoção destas cenas surge do conflito entre o desejo dos pais e o destino dos filhos, que está presente desde o início dos tempos e vemos e sentimos isso em nossa vida. A emoção que temos vendo Game of Thrones hoje é a mesma emoção que um grego do período clássico sentia ao ver uma cena da Guerra de Troia num jarro de barro, nas paredes de um templo ou mesmo no teatro. Assim, a busca pelo sentido das relações humanas, como por exemplo, as relações entre pais e filhos, é a função do Mito. Uma vez que essas relações existem até hoje, e como precisamos de algo que nos ajude a lidar com elas, não tanto pelo pensar, mas sim pelo sentir, o Mito continua vivo apesar de todos os nossos avanços racionais e tecnológicos (Jung, 200o). E a necessidade humana pelo Mito é tão grande que inclusive pagamos para ter contato com ele, por exemplo, assinando canais fechados para assistir Game of Thrones ou Guerra nas Estrelas.

E qual a relação então entre o Mito e a Ciência? Nós poderíamos perguntar... Essa relação existe, no fato de que o Mito nos ajuda na busca pelo sentido da necessidade humana pelo conhecimento (Capra, 1995; Campbel, 1990). E o conhecimento, como todos sabemos, é algo extremamente precioso para Ciência. Mas então entramos em outra questão: o que o Mito tem a nos dizer sobre o conhecimento? O Mito nos diz que o conhecimento é algo perigoso, algo que deve ser tratado com cuidado, ou até mesmo, algo que seria melhor não ter contato. Por isso não é raro encontrar entre diversas mitologias, de diferentes povos, a associação entre o conhecimento e algum tipo de maldição.

O Mito de Prometeu é um exemplo disso: na Mitologia Grega Prometeu era um Titã que por amor a humanidade, roubou o fogo dos Deuses e entregou aos homens (Graves, 2008). O Fogo não era apenas um elemento da natureza, mas uma representação simbólica do conhecimento, pois é aquilo que permitiu a supremacia dos homens sobre os outros animais, colocando-os (graças ao conhecimento que adquiriram) em uma condição mais próxima dos Deuses. Zeus, o pai de todos os Deuses se irritou com a atitude de Prometeu e o condenou a passar a Eternidade acorrentado em uma pedra, onde uma águia viria todos os dias comer um pedaço de seu fígado, que se regenerava durante a noite. Assim o castigo de Prometeu, por ter despertado a consciência dos homens, foi passar a eternidade em sofrimento. E para 
os homens, os Deuses reservaram um castigo parecido. Como punição por terem recebido o fogo de Prometeu, os Deuses enviaram uma Kakí Omorfiá. No Mito de Prometeu a punição dos homens foi receber a primeira mulher chamada Pandora que trouxe consigo um jarro com todos os males que humanidade conhece, e quando o jarro foi aberto (devido a grande curiosidade de Pandora) todas as desgraças se espalharam pelo mundo. A partir desse dia convivemos com todas as mazelas que conhecemos.

Na verdade, a punição dos Deuses não foi a mulher, não foi Pandora e sua curiosidade, os homens foram punidos com a Kakí Omorfiá, que em grego significa uma "Beleza má". Ou seja, os Deuses deram aos homens algo tão irresistível, que mesmo sabendo que Pandora trazia consigo o mal, os homens não conseguiram mandá-la embora, e tiveram que aguentar as consequências dessa escolha.

Os Deuses deram aos homens, por intermédio de Pandora, mais conhecimento, só que conhecimento sobre o mal, e os homens não poderiam culpar os Deuses por esse conhecimento, porque tiveram a escolha de mandar Pandora embora, mas eles não conseguiram, porque ela era irresistível, ou seja, o conhecimento é irresistível.

Nas entrelinhas é como se os Deuses dissessem: "A ignorância era a felicidade, mas vocês homens desejaram conhecimento, pois agora aguentem as consequências desse conhecimento, e de hoje em diante vocês terão a consciência de tudo, até mesmo da infelicidade, das desgraças e da dor". Este "castigo" sofrido pelos homens, também pode ser encontrado em outras Mitologias como, por exemplo, a JudaicoCristã.

No início de tudo, Deus (Jeová) no Genesis criou um paraíso. Em seguida criou um homem e uma mulher para habitar esse paraíso e gozar de tudo que aquele lugar poderia oferecer. Adão e Eva podiam fazer o que quisessem, e comer as frutas de todas as árvores do paraíso, menos de uma, a Árvore do Conhecimento. No Gênesis consta que Deus advertiu Adão e Eva dizendo, "Comerás livremente o fruto de qualquer espécie de árvore que está no jardim; contudo, não comerás da árvore do conhecimento do bem e do mal, porque no dia em que dela comeres, com toda a certeza morrerás!" (Gênesis 2:16). E todos nós conhecemos o resto da história... a serpente tenta Adão e Eva, que comem do fruto proibido e são expulsos do paraíso, e nós até hoje sofremos por conta desse pecado original, sentindo dor na hora do parto e ganhando o pão com o suor do nosso rosto. Ou seja, do mesmo modo que no Mito Grego, no Mito Judaico-Cristão, o preço a pagar pelo conhecimento é o sofrimento.

Esses são apenas dois exemplos, mas existem vários outros mitos de outras culturas onde a história se repete... a humanidade vivia na felicidade, porém na ignorância, e em algum momento ela teve a chance de escolher se queria continuar 
nessa condição ou se queira mudar. E a humanidade escolhe mudar, escolhe ter o conhecimento, só que com isso perde a felicidade.

E então nos perguntamos, por que razão os povos antigos tinham essa visão tão trágica em relação ao conhecimento? Porque eles consideravam o conhecimento como algo essencialmente perigoso. Basicamente por duas razões: $\mathbf{1}^{\mathbf{0}}$ - $\mathbf{o}$ conhecimento nos revela a nossa condição de miséria enquanto ser, o conhecimento nos mostra que não somos Deuses, não somos Titãs ou Gigantes, somos apenas Homens, mortais, falhos e confusos. E para ilustrar isso temos como exemplo o Eclesiastes, um discurso que é atribuído a Salomão, que pode ser visto dentro de um contexto da mitologia judaica. Salomão que foi Rei de Israel é enfático ao identificar como consequência do excesso de conhecimento a vacuidade existencial do homem. "Vaidade das vaidades, diz o Eclesiastes, tudo é vaidade! ... Eis que eu me engrandeci e sobrepujei em sabedoria a todos os que viveram antes de mim em Jerusalém; na verdade, o meu coração contemplou abundantemente a sabedoria e a ciência. E apliquei o meu coração a conhecer a sabedoria e a conhecer os desvarios e as loucuras e vim a saber que também isso era aflição de espírito. Porque, na muita sabedoria há tristeza; aquele que amplia o seu saber, amplia também o seu pesa" (Eclesiastes 1:5-16).

Salomão nos mostra a angústia que o conhecimento pode nos trazer quando, depois de dedicarmos uma vida inteira para compreender algo (como por exemplo, a natureza humana), nos deparamos com algo que não gostamos muito de saber ou ver.

E o $2^{\circ}$ motivo pelo qual os antigos mitos nos alertavam sobre o perigo do conhecimento, deve-se a continuidade desse primeiro motivo, que é a constatação da condição humana. Ou seja, quando adquirimos um pouco mais de saber, de consciência sobre algo, tendemos a achar que estamos nos tornando Deuses. Quando temos consciência de que sabemos mais do que os outros, ou seja, quando de algum modo nós nos percebemos superiores aos nossos iguais, corremos o risco de nos tornar orgulhosos e arrogantes.

O orgulho e arrogância entre os gregos antigos tinha um nome claro, era chamado de Hybris. A Hybris (o orgulho e a arrogância, por querer ser mais do que você é) era algo imediatamente punido pelos Deuses, geralmente, com a loucura ou com a morte (Brandão, 1993). Por isso, os gregos e consequentemente os romanos criavam mecanismos para evitar que pessoas, devido a sua condição de poder, cometessem a Hybris, atraindo assim a ira dos deuses. Um exemplo disso era o banimento temporário que ocorria em Atenas, sempre que alguém alcançasse um grande poder político/econômico. Outro exemplo, usado entre os romanos, era o chamado Triunphus Romanus, que era uma comemoração civil/religiosa realizada em homenagem a algum grande general que conseguia uma expressiva vitória militar contra um inimigo estrangeiro. Para receber um Triunfo, o general precisaria 
ter vencido pelo menos 5 mil tropas inimigas, o que inclusive, lhe dava o direito, dependendo do caso, de receber o título de imperador. O Triunphus Romanus era uma espécie de cortejo que tinha início fora dos muros de cidade, onde todos os despojos de guerra eram apresentados aos cidadãos, em conjunto com os símbolos dos inimigos derrotados (e muitas vezes os próprios reis e generais inimigos capturados). O General que receberia o Triunphus tinha o rosto pintado de vermelho e entrava na cidade passando por uma entrada, um arco triunfal, em uma biga puxada por pelo menos 4 cavalos, seguido pelas suas tropas. Na biga em que o general estava, também se encontrava um escravo localizado atrás dele segurando uma coroa de louros, representando a glória do general. De tempos em tempos durante o cortejo, enquanto toda a população romana exaltava o homenageado, esse escravo se aproximava do ouvido do general e dizia: "memento mori" (lembra-te que és mortal).

Essa estratégia romana servia para evitar que o orgulho e a arrogância tomassem conta do espírito do homenageado, fazendo ele se perder na própria loucura de achar que, por ter conseguido um grande feito militar, poderia se considerar algo mais do que um homem.

O que era verdade para o excesso de poder econômico, político ou militar, no mundo antigo, também era verdade para o excesso do conhecimento. A mensagem era clara, cuidado com o orgulho e a arrogância, lembra-te que és mortal, e o conhecimento que você acumulou, não lhe dá poderes para você ser igual a um Deus.

Por isso o conhecimento era visto pelos povos antigos, como algo que fascinava e assustava ao mesmo tempo, daí a referência a "beleza má" dos gregos, daí a advertência, o conhecimento é uma "beleza má", ele te seduz, ele te fascina, ele torna tua vida mais fácil, ele te envolve, mas... se você não tomar cuidado ele te destrói (como o fogo), porque o conhecimento também tem a capacidade de nos fazer acreditar que somos algo que não somos, ou seja, um Deus.

Depois de tudo que foi exposto, pode-se pensar: o conhecimento é uma coisa terrível, a ânsia por encontrá-lo nos lançou numa existência de dor e sofrimento. Melhor seria se a humanidade tivesse permanecido na ignorância. Pode ser... mas a questão é, se lamentar pelo que aconteceu, e conjecturar como poderia ter sido, não vai resolver o nosso problema, o que precisamos fazer é buscar um meio de sair dessa condição onde nos encontramos. E para isso novamente o Mito nos oferece um caminho, uma solução para escaparmos da dor, da angústia e do sofrimento. Um exemplo desse caminho é o Mito de Hipócrates.

Hipócrates já prescrevia que no mais profundo da doença existe a essência para a cura, e que o antídoto só pode ser extraído do próprio veneno. Ou seja, se o conhecimento foi o que nos lançou no mundo de sofrimento, não existe outra saída, 
não existe outro remédio, o único caminho para a solução do problema é pelo próprio conhecimento. Por isso vemos a insistência entre os gregos, em relação a suas práticas de cura. O primeiro remédio para qualquer tratamento era a busca pelo autoconhecimento. Por isso que em Epidauro, lugar do grande centro médico do mundo grego clássico, a administração da panaceia (que seria os remédios extraídos de plantas e minerais) e todo o tratamento era feito em etapas. Primeiro todo doente deveria fazer um sacrifício a Asclépio (Deus da medicina), e depois se dirigir a um lugar específico no templo, para dormir e ter um sonho que posteriormente seria interpretado pelos sacerdotes. A crença era de que esse sonho seria enviado por Asclépio, e nele estaria contido os indícios do tratamento que precisaria ser feito. Nota-se que a ideia Mítica era a de que a cura para a doença já se encontrava dentro do próprio doente, sendo que o primeiro passo do tratamento era o doente se conhecer (por meio do sonho), ou seja, o doente deveria adquirir consciência de si. Essa ideia foi profundamente adaptada para sociedade contemporânea, por um dos maiores cientistas do século XX, Sigmund Freud com a Psicanálise. Por isso que a inscrição que existia na entrada do oráculo do templo de Apolo, em Delfos, se tornou a marca psicológica da civilização ocidental: "Conhecete a ti mesmo" que ao mesmo tempo era uma advertência e o conselho do oráculo.

O Mito cumpre a sua função e nos dá o sentido sobre, já que temos essa ânsia na busca pelo conhecimento, essa vontade insaciável de sempre querer saber mais. No passado nós fomos expulsos do paraíso, nós fomos feridos pelo conhecimento, porém essa feriada, essa maldição, essa doença, só pode ser curada pela própria substância que causou o ferimento, ou seja, pelo próprio conhecimento.

Mas se o conhecimento é perigoso (como o fogo que Prometeu deu aos homens), lidar com esse elemento divino não é uma tarefa simples, homens comuns tem dificuldade em realizar essa tarefa, por isso, a tarefa de lidar com conhecimento precisa ser realizada por pessoas especiais. E os gregos tinham um nome específico para pessoas especiais, eles chamavam de Heróis.

E o que é um Herói dentro da mitologia grega? O Herói pode ser alguém com uma ascendência divina, como é o caso de Aquiles, filho da ninfa Tétis com o mortal Peleu, que foi para a guerra de Tróia em busca da glória eterna. Mas o Herói também podia ser uma pessoa comum que devido a suas características individuais se lançava em tarefas árduas, visando um Bem para a coletividade, como é o caso de Odisseu, que devido a sua grande engenhosidade garantiu a vitória grega sobre os troianos a partir da construção do famoso cavalo de Tróia. Odisseu não foi à guerra por glória, como no caso de Aquiles, ele era só um homem, tinha família e filho. Ele só foi à guerra para proteger o seu reino, a cidade de Ítaca, contra a ira de Agamêmnon, rei de Micenas, que estava organizando um exército grego contra os troianos. 
Então vemos que para os Gregos, um Herói podia ser um homem comum, com a única diferença de que era uma pessoa comum que fazia coisas extraordinárias. E é aqui que podê-se estabelecer a principal ligação entre o Mito e a Ciência na contemporaneidade, pois o Cientista atual encarna o arquétipo do Mito do Herói. Aqui nos deparamos com um exemplo de como o mito se encontra vivo hoje, e de como a personificação do Herói, por exemplo Odisseu, pode ser visto na figura do cientista. Alguém que lida com algo perigoso, que muitas vezes sacrifica sua condição pessoal de vida em nome de um bem para a sociedade.

Nós hoje não temos mais em nosso convívio monstros, górgonas, quimeras, gigantes, dragões ou demônios, atormentando a humanidade, por isso não precisamos mais de Heróis com elmos e escudos mágicos, dados pelos deuses, ou com armaduras e espadas forjadas no calor mais intenso, da mais profunda forja do inferno. Nossos monstros hoje tem outro nome, eles se chamam vírus, bactérias, câncer, escassez de alimentos, crises energéticas, neuroses, psicoses, gestão da informação, etc. Por isso que os Heróis que temos hoje não são mais pessoas atrás de escudos segurando uma lança, são pessoas atrás de computadores, segurando uma caneta.

O Cientista, assim como o herói clássico, carrega um fardo, assume riscos. Ele lida com algo perigoso, algo que pode ajudar imensamente a humanidade (o conhecimento, o fogo de Prometeu), mas que para ele, enquanto indivíduo, pode ter um preço muito alto.

Assim, a relação entre o Mito e a Ciência evidencia o quando constatamos que o Mito nos ajuda a compreender nossa atual situação existencial na era da tecnologia. Existe sobre nós uma maldição, a maldição do conhecimento, os principais males que nos afligem na era moderna são decorrentes do nosso conhecimento. Nós fizemos a bomba atômica, não foi nenhum demônio que criou esse instrumento de destruição em massa, fomos nós mesmos, simples homens. Portanto, nossa única possibilidade de redenção será pela via do conhecimento. Só que para lidar com essa maldição, nós precisamos de Heróis que estejam dispostos a correr o risco de sacrificar a sua vida em nome de um Bem comum.

O Herói que hoje se personifica na figura do cientista, o Herói que como nos lembra Campbel (1990), no sentido clássico grego, não é somente alguém com poderes supra-humanos, mas é alguém comum que se desprende da vida comum assumindo riscos pessoais. É aquele que assume o risco das consequências da sua ação pelo bem dos outros.

\section{Referências}

BOCK, A. M. B.; FURTADO, O.; TEIXEIRA, M. L. T. Psicologias: uma introdução ao estudo da psicologia. São Paulo: Saraiva, 2003.

BRANDÃO, J. S. Mitologia grega. Vol. III. Petrópolis, RJ: Vozes, 1993. 
CAMPBEL, J. O poder do mito. São Paulo: Palas Athena, 1990.

CAPRA, F. Sabedoria incomum. São Paulo: Pensamento, 1995.

CHAUÍ, M. Convite à filosofia. São Paulo: Ática, 2004.

GRAVES, R. O grande livro dos mitos gregos. São Paulo: Ediouro, 2008.

JUNG, C. G. O homem e seus símbolos. Rio de Janeiro: Nova Fronteira, 2000.

Submissão: 12. 12. 2019 / Aceite: 14. 05. 2020 